\title{
- An Unusual Occurrence of Pyogenic Granuloma
}

\section{Preethi Murali' ${ }^{1}$ Uma Ravichandran²}

$$
\begin{aligned}
& \text { IJCRR } \\
& \text { Section: Healthcare } \\
& \text { ISI Impact Factor } \\
& \text { (2019-20): 1.628 } \\
& \text { IC Value (2019): } 90.81 \\
& \text { SIIF (2020) = 7.893 } \\
& \text { C) () - } \\
& \text { Copyright@IJCRR }
\end{aligned}
$$

'Professor, Department of Oral Pathology\& Microbiology, Meenakshi Ammal Dental College \& Hospitals, Meenakshi Academy of Higher Education and Research, Chennai 6ooo95, India; ${ }^{2}$ Consultant Dental Surgeon, Chetanaa's Dental \& Cosmetic Care, Chennai 6ooo37, India.

\section{ABSTRACT}

Introduction: Pyogenic granuloma (Granuloma pyogenicum) is one of the inflammatory hyperplasias seen in the oral cavity. This term is considered a cryptonym because the lesion is unrelated to infection and it can arise in response to various stimuli which can either be a low-grade local irritation or traumatic injury due to local factors. It is non-neoplastic in nature. Pregnancy tumour, pregnancy epulis and gingival epulis are the various other terms used when arising in pregnant women.

Case Report: Here we present a case report of a 24-year-old female who developed a pregnancy tumour in the tongue which is an uncommon site and did not regress after parturition.

Conclusion: The growth continued to remain due to traumatic factors and was surgically excised.

Key Words: Pregnancy tumour, Pyogenic granuloma, Coroplast, traumatic, Epulis, Tongue growth

\section{INTRODUCTION}

Pyogenic granuloma (Granuloma Pyogenicum) is one of the inflammatory hyperplasia seen in the oral cavity. This term is a misnomer because the lesion is unrelated to infection and, arises in response to various stimuli such as low-grade local irritation, traumatic injury or local factors. ${ }^{1}$ It is non-neoplastic. It is the most common gingival tumour in the Lips. The buccal mucosa is the next common site and occasionally it occurs in the tongue. It is slightly more common on the maxillary gingiva. Anterior areas are more frequently affected. It is much more common on the facial aspect of the gingiva than the lingual aspect. ${ }^{2}$ Pregnancy tumour, pregnancy epulis and gingival epulis are the various other terms.

\section{CASE REPORT}

A 24-year-old female presented with a history of a small growth in the tongue for the past 9 months. She first developed the growth when she was in her second trimester. The growth did not resolve after her parturition. The patient also complained of pain and discomfort during mastication and speech. The growth was ulcerated and was bleeding often.
The patient was afebrile, without any underlying systemic disease. She didn't have any relevant medical or family history. On intraoral examination, the growth was exophytic, pedunculated measuring $1 \times 1 \mathrm{cms}$, and bled on slight probing (Fig 1). She had a fractured maxillary lateral incisor corresponding to the lesion which seems to have aggravated the growth and resulted in ulceration. The growth was provisionally diagnosed as Pregnancy Tumor/ Pyogenic Granuloma. The patient was asked to rinse the mouth with chlorhexidine gluconate mouthwash and the local application of topical anaesthetic gel along with antibiotics and analgesics were prescribed. After a week, the margins were narrowed, and the ulceration was healed. However, the growth persisted. (Fig 2).

Considering the smaller size and patient ease, an excisional biopsy was done under local anaesthesia. Coronoplasty was done in the associated tooth. The histopathologic diagnosis confirmed the clinical diagnosis of Pyogenic Granuloma. The patient was asked to continue the prescribed medications for 7 days during the first post-operative week. The growth resolved and did not recur in 2 months of follow up. (Fig 3).

\section{Corresponding Author:}

Dr. Preethi Murali, Professor, Department of Oral Pathology\& Microbiology, Meenakshi Ammal Dental College \& Hospitals, Meenakshi Academy of Higher Education and Research, Chennai 600095, India; Email: drpreethy@gmail.com

ISSN: 2231-2196 (Print)

Received: 12.04 .2021
ISSN: 0975-5241 (Online)

Revised: 09.06 .2021
Accepted: 05.08.2021
Published: 20.11 .2021 


\section{DISCUSSION}

Pregnancy tumour of the oral cavity develops in up to $5 \%$ of pregnancies, hence the terms" pregnancy tumour" and "granuloma gravidarum" are often used(2) Though they are quite common in almost all sites of the oral cavity, unusual sites like nasopharynx have also been reported ${ }^{3}$ The tumour usually grows rapidly and a direct relationship has been established between the growth rate of the tumour and the decreased level of estrogen and progesterone, occurring during pregnancy. ${ }^{1,2,3,4}$ The reason for pregnancy tumour can be due to the production of vascular endothelial growth factors in macrophages as a result of Estrogen. ${ }^{5,6}$ In this case, the lesion was initially small and wasn't ulcerated. Due to the presence of a traumatic factor, there was ulceration causing high discomfort to the patient and making inconvenience in activities like mastication and phonetics. Coronoplasty was done on the fractured tooth as an attempt to eliminate the causative agent for ulceration. Bacterial origin is also an etiologic factor for pyogenic granuloma. The presence of gram-positive and gram-negative bacilli in ulcerated forms pyogenic granuloma was demonstrated by Bhaskar and Jacoway. ${ }^{7}$ Oral pyogenic granuloma has capillary growth inside a mass of granulation tissue, this justifies that pyogenic granuloma is a misnomer.

\section{CONCLUSION}

Although pyogenic granuloma is non-neoplastic, it arises in response to various stimuli. In this case, in addition to the hormonal factor, the traumatic factor of the fractured maxillary lateral incisor aggravated the growth. Removal of irritants that cases the tumour is the major line of treatment. Excisional surgery is the most common treatment of choice for pyogenic granuloma.

\section{ACKNOWLEDGEMENT}

Authors acknowledge the immense help received from the scholars whose articles are cited and included in references of this manuscript. The authors are also grateful to authors/ editors/publishers of all those articles, journals and books from where the literature for this article has been reviewed and discussed.

\section{Source of Funding: Self}

\section{Conflict of Interest: Nil}

\section{Authors' Contribution:}

Dr. Preethi Murali - Case preparation and manuscript formation

Dr. Uma Ravichandran- Photography and technical assistance

\section{REFERENCES}

1. AzinMirzadeh,Nader Navabi, MoloukTorabi, Parizi. The unusual occurrence of Pregnancy Tumor on the tongue. Iran J Public Health. 2014;.43(6):845-846.

2. Hamid JafarZadeh,MajidSanatkhani and NashinMohatsham. Oral Pyogenic granuloma: a review. J Oral Sci.2006;48(4):167175.

3. Fernandes VL, Pinto NM, Sanzgiri VB, Khandholkar P, Sukhthankar, I.R et al . A rare case report of Pyogenic granuloma of the tongue(International Journal of Otolaryngology and Head \&Neck Surgery. 2018;7:75-79.

4. Hartzell MB. Granuloma Pyogenicum. J Cutan Dis Syph. 1904; $22,520-525$

5. Eversole LR (2002) Clinical Outline of oral pathology; diagnosis and treatment. $3^{\text {rd }}$ ed, BC Decker, Hamilton, 113-114.

6. Oral pregnancy Tumor, Shailesh et al. Contemporary Clin Denti. 2010 Jul-Sep; 1(3): 190-192.

7. Bhaskar SN, Jacoway JR. Pyogenic granuloma - Clinical features, incidence, histology, and the result of treatment: Report of 242 cases. J Oral Surg. 1966;24:391-8.

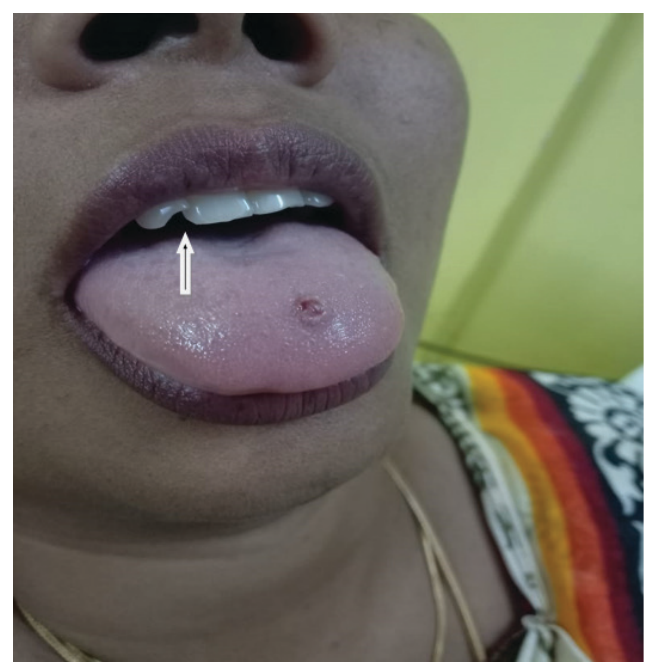

Figure 1: Growth on Dorsum of tongue with adjacent Sharp tooth. 


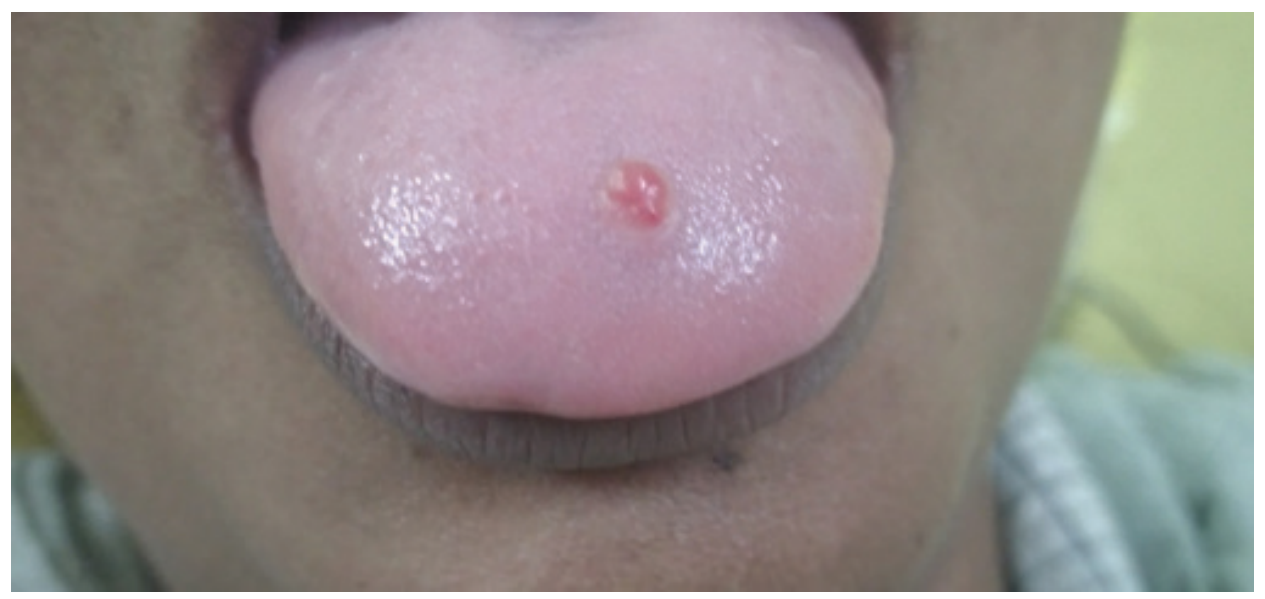

Figure 2: Healing phase post medication.

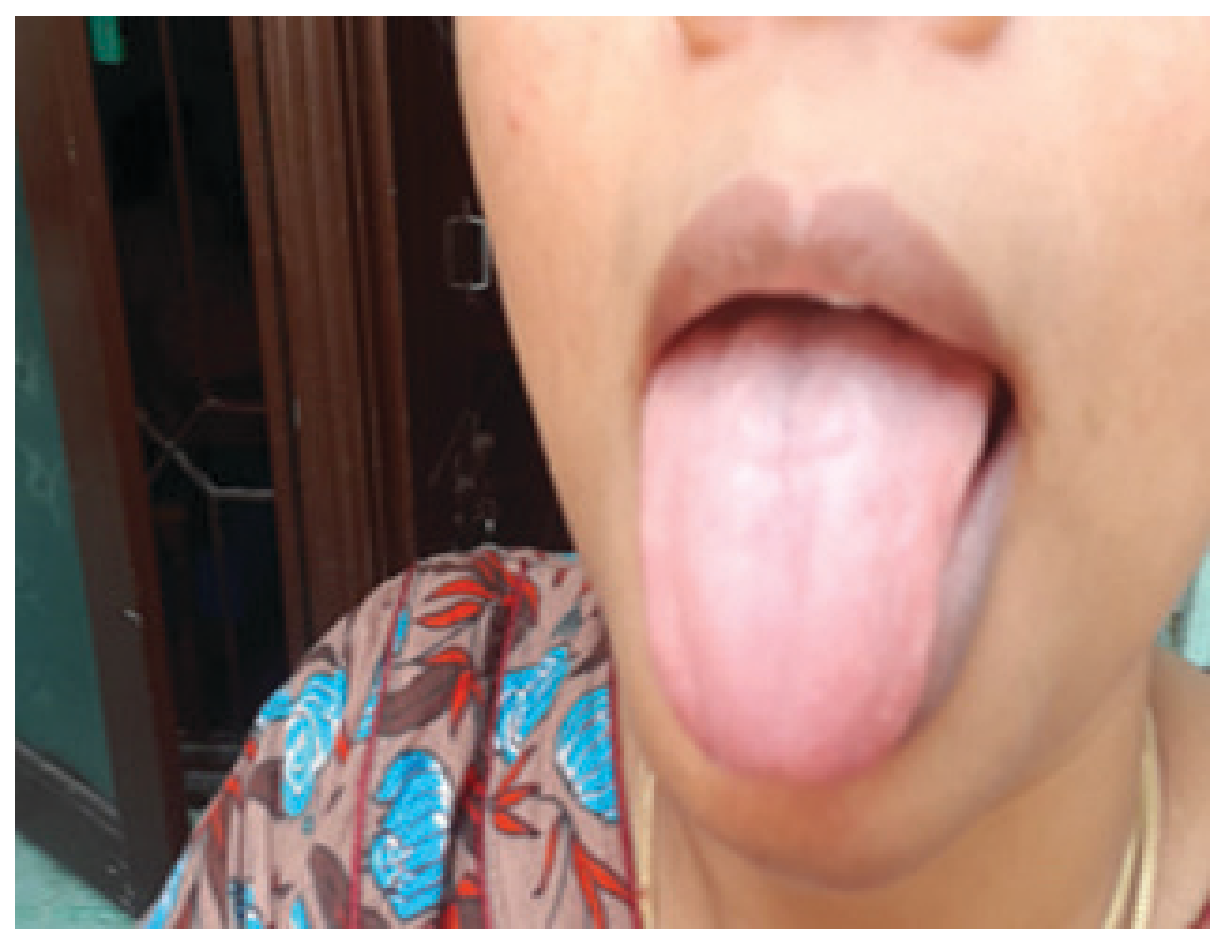

Figure 3: Healed growth and ulcer after 2 months follow up. 